\title{
The Cultural Meaning and Aesthetic Implication of Chinese Cheongsam
}

\author{
Zhexin Liu \\ Zhuhai College of Jilin University \\ Zhuhai, China
}

\begin{abstract}
This paper analyzes the evolution process of cheongsam from the historical level, and explores the reasons for its change and development in combination with the characteristics of the nation and the times. In the dynamic context, we should look for the stable core and changing factors in the connotation of Chinese culture represented by the cheongsam, fully understand the characteristics of the cheongsam, and excavate the beauty of the east. While strongly affirming the cultural and aesthetic value of the cheongsam, it also gives an objective evaluation of the limitations of the cheongsam, combining with the current popular culture and social reality, to seek the way of the change of the cheongsam. Let the cheongsam improve gradually and consolidate its position in the international culture and art hall.
\end{abstract}

Keywords-cheongsam; cultural meaning; aesthetic implication

\section{INTRODUCTION}

As the classic of Chinese traditional dress, cheongsam is very representative of the nation, and full of elegant, dignified and demure temperament advocated by the East. After hundreds of years of baptism, it is still gorgeous blooming. The elegant image of the cheongsam not only makes the Chinese people dump, but also get the love and praise of the people of the world. Many famous western fashion designers have been inspired by the Chinese cheongsam. It is no accident that cheongsam is still able to occupy the place of modern costume design with its unique charm. Like other national cultures, cheongsam is the treasure of Chinese traditional culture.

\section{THE ORIGIN AND EVOLUTION OF CHEONGSAM}

"Robe" originally refers to a long garment worn on the outermost part of the body under the shoulder. According to the relevant information, there are records in Ancient and Modern Notes that "Robe" existed in the early Emperor Shun period. Cheongsam originated in the Qing Dynasty, the original meaning is the robes of banner men. After the Qing Tai $\mathrm{Zu}$ Nur $\mathrm{Ha}$ Che established the gold regime, the "Eight Banners system" was carried out in order to maintain the rule of eight banners, and the Manchu people were called the banner men at that time, and the traditional robes worn by the Manchu people were called "cheongsam", and then the cheongsam was specifically referred to as the dress of the women suit.
The cheongsam was born in the Qing Dynasty eight banners female loose, straight lines of robes. Now our socalled cheongsam, born in the 1920s, in shape, style has been greatly different from the Qing Dynasty "cheongsam". With the passage of time, under the influence of many factors, modern cheongsam is becoming more and more exquisite and fashionable in the continuous "improvement", and has become the representative of Chinese traditional dress. Dress even belonging to clothes, fitting the plane cut of female body curve, exquisite stand collar plate buckle, the slanting skirt and slant with unique characteristics-in the perfect combination of many elements, cheongsam fully shows the dignity and elegance of the oriental women. Classic and fashion, soft and smart, elegant and sexy style in a cheongsam with its unique oriental charm becomes the classic of the world clothing.

In the early Qing Dynasty, the style of the cheongsam was simple and natural with the wide body, the no fork side, the round collar, and the open right lapel in "Fig. 1". With the blending of Manchu and Han culture, influenced by dress making technology and adornment tradition of Han, the style of cheongsam has changed to a certain extent. The specific manifestations are: the style of clothing has gradually become exquisite and gorgeous, with bright colors and fine patterns; the previous round collar has changed into a collar, gradually becoming taller, and the shape of the collar like Yuanbao; although the clothes are still looser, they pay more attention to the details in the production of the clothes. Slit, neckline, cuff, skirt and so on are paid more attention to edge, the more beautiful embellishment it is in "Fig. 2".

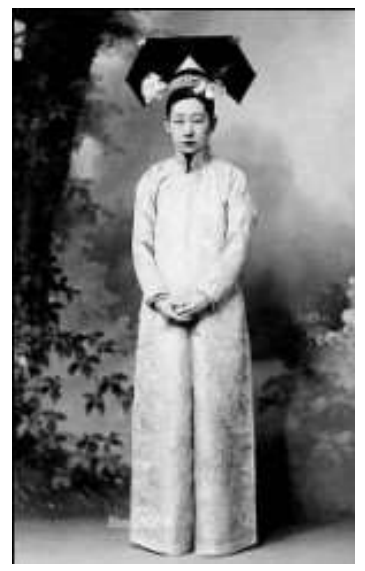

Fig. 1. Manchu attire in Qing Dynasty. 


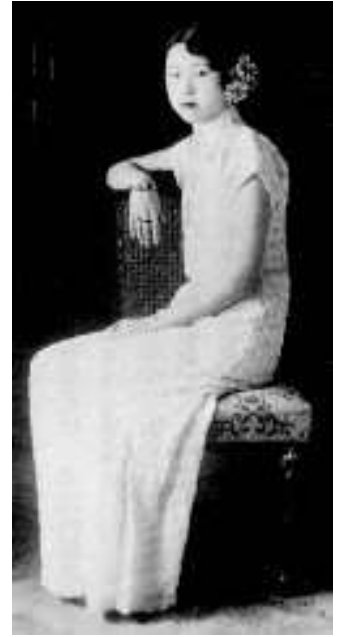

Fig. 2. Manchu attire in Qing Dynasty.

With the success of 1911 Revolution, the infiltration of western culture was gradually accepted by Chinese people. In April 1929, the national government designated the cheongsam as a national suit. In 1920s-1930s, the traditional style of Chinese cheongsam has changed greatly due to the influence of European and American dress culture. Because of the influence of the three-dimensional cut of the western dress, the tailoring of the garment body is no longer the former loose style, but the waist body is tightened, as close to the body as possible. At the same time, under the impact of multiculturalism, people's design inspiration has been enriched, the style of cheongsam began to diversify, mainly in the collar, sleeve, length and other parts of the length and style changes. By the 1940s, the style of the cheongsam had not changed much from the $1930 \mathrm{~s}$, but the style had become more concise (Fig. 3). Some scholars infer that this may be due to the change of women's social status and more social activities after the 1940s, and the need for simplicity and convenience in dress. It can be said that cheongsam in the recent times laid the foundation of the modern cheongsam. Although the modern cheongsam has carried out a variety of wonderful interpretations in the hands of the designers, there is no change from the traditional cheongsam, and the form and dress tradition of the cheongsam are still retained.

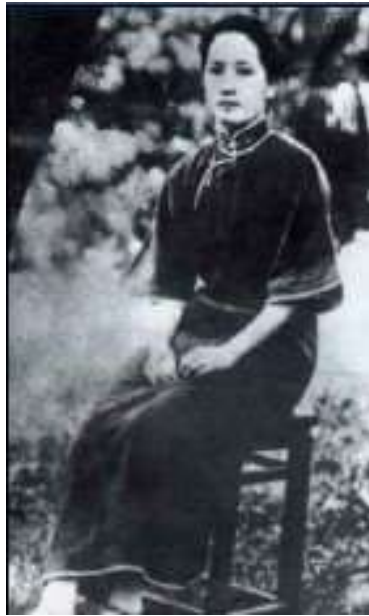

Fig. 3. Cheongsam in the Republic of China.

In the 1960s and 1970s, the culture of cheongsam once declined, mainly because of the impact and influence of western clothing. In this period, western dress has occupied the clothing market and aesthetic orientation of Chinese people to a great extent. In the late 1980s and early 1990s, due to the wonderful interpretation of female stars in film and television works, the Chinese retro complex was again awakened by cheongsam, and the charm of cheongsam was discovered again, becoming the focus of popularity. At the same time, the beauty of cheongsam is gradually discovered and loved on the international stage. The classic Chinese elements in the cheongsam have inspired many of the best designers in the West. International fashion guru Saint Laurent once said: "our Western art can be given a lot by China, that influence is multifaceted and obvious, without China, our civilization can never reach the present situation." When the unique classical charm and modern design concept meet, the style of Chinese cheongsam is displayed incisively and vividly.

Looking back on the evolution of cheongsam, it is not difficult to find that the needs of people's aesthetics, the influence of the blending of national culture, the influence of historical politics and the influence of western dress culture have become the important factors to promote the continuous change and improvement of cheongsam.

\section{TECHNOLOGICAL CUlture IN THE DESIGN OF CHEONGSAM}

We often admire the beauty of various national costumes. In fact, the beauty of a thing lies not only in its shape, but also in its inner meaning-like a person's irreplaceable temperament, self-preservation. Like the traditional dress of other countries, the cheongsam carries the cultural accumulation of the Chinese nation since thousands of years, its shape, its color, material and decoration, is not the refinement and sublimation of Chinese culture.

The making of cheongsam contains a lot of traditional Chinese craftsmanship, and the unique tailoring way perfectly highlights the curvy, collar, sleeve, skirt, slit and other details of every part of a woman's body, all of which are unique elements of the cheongsam. 


\section{A. Shaping}

Tailoring: even cut is unique to the tailoring style of cheongsam. The cloth of the flat spreading is cut off, the clothes piece is smooth, and the front and rear clothes pieces are connected with the two sides of the garment body through the shoulder and the garment body, so that the front and back clothes pieces are greatly different from the three dimensional clipping of the western clothing, as shown in "Fig. $4 "$.

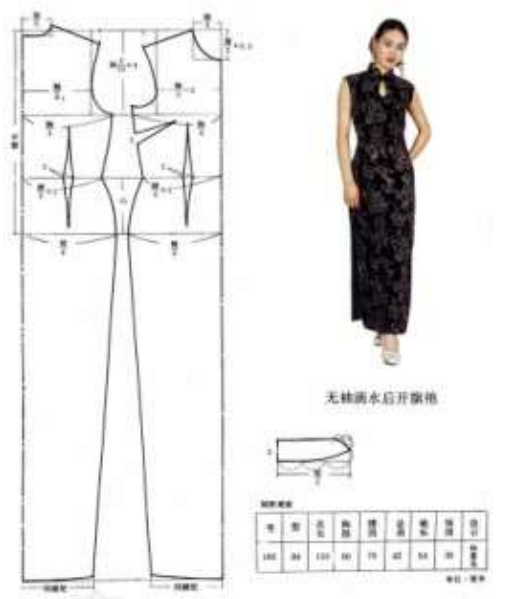

Fig. 4. Tailoring of cheongsam.

Modelling: cheongsam can best display the beautiful figure of a woman, in the shape of the "province" mainly through the adjustment to achieve the effect of showing the body curvemainly focused on the chest province, waist province, rib province and sleeve long province processing. We often say that cheongsam should be tailored to better integrate the actual curves of the human body and the most appropriate treatment of the relevant parts.

\section{B. Details}

Collar: the collar of a woman's dress can well contrast the neck features. Cheongsam collar part of the production is very elegant, in addition to high and low collar, but also according to the angle divided into inclined and barrel type, square or round collar angle, which can be described as a variety of patterns.

Placket: like collar, the style of cheongsam is also varied. The more classical styles include lute lapel, big skirt, slanting lapel and so on. Since ancient times, China's "right position", "right as the top", thus formed a right-cut tradition. The production process of placket is very complicated, mainly including "insert" and "roll", the Republic of China has the "18 rolling" theory.

Sleeve: because the structure of the cheongsam is basically stable, in addition to the choice of material, color and dress length, the style difference of the cheongsam is mainly reflected in collar, placket and sleeve. According to the length and length of the sleeves, the sleeves of cheongsam can be divided into sleeveless, short-sleeved, medium-sleeved, longsleeved, etc. According to the style, there are horn sleeves, double sleeve and so on. In the production process of the sleeve, the embellishment and decoration of the sleeve is also very important.

Slit: the slit on both sides of the cheongsam is the key to women's charm. The original cheongsam did not slit, until the modern times, the practice of cheongsam slit gradually popular. After modern times, cheongsam was no longer the loose style of the past. Instead, it was replaced by a close-fitting style that showed the body's curves to the greatest extent. It can be inferred that the cheongsam's slit should initially be for convenience of movement. But that's why women in cheongsam are walking around with their legs now hidden, adding a subtle sensuality to the cheongsam. Cheongsam has high and low slits, sometimes close to the buttocks, sometimes near the knee.

Flower buckle: the Chinese flower buckle belongs to a kind of "Chinese knot", it can be described as the finishing touch in the making process of cheongsam. Small and exquisite-made floral buckles, embellished in cheongsam's buckle, add a Chinese classical charm in "Fig. 5".

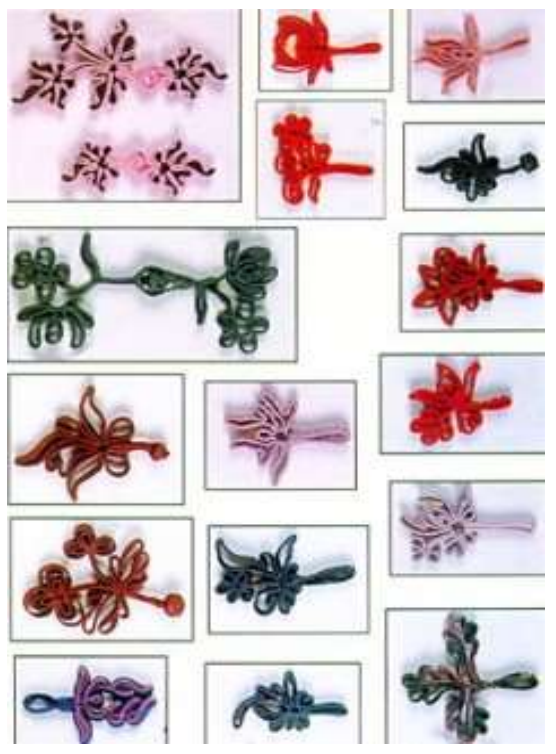

Fig. 5. Floral buckle.

Fabric: cheongsam is mostly made of Chinese silk fabrics, such as brocade, satin, crepe, silk, etc.

Pattern: the pattern on the cloth of cheongsam is popular with the traditional style of the Chinese people. Such as the symbol of auspicious longevity, flowers and other patterns, in addition to natural flowers and plants are also often loved by people.

Color: after modern times, the age mark of color classes no longer exists; people can choose the color of clothes according to their own preferences. Compared with other gorgeous colors, red, cyan and other show strong national characteristics. 


\section{The National Culture ConNotation AND AESTHETIC CHARACTERISTICS OF CHEONGSAM}

\section{A. The Psychological Characteristics of Traditional Chinese Aesthetics Reflected by Cheongsam}

The western culture originated in ancient Greece and ancient Rome, upholding the body of bodybuilding. Westerners are beautiful with women's breast and fat buttocks. So the Western costume design is very strong sense and is good at attracting people's eyeballs with "exposed" dress. Different from western culture, Chinese culture, deeply rooted in Confucianism, affects every aspect of people's life. As the representative of Chinese traditional dress, cheongsam is produced and developed under this cultural background. In a sense, cheongsam itself is the "spokesman" of ConfucianismThe culture of cheongsam shows vivid national spirit. It is the representative of a kind of national culture idea. Cheongsam lines smooth, natural and simple shape, no sharp corners, color coordination, different from the Western sexy clothing as exciting eyeball, but can make people feel comfortable and peaceful. This style of cheongsam coincides with the Confucian doctrine of the mean. The key to the middle course lies in peace, stability and depth. Undoubtedly, cheongsam is the ideal dress model of this spirit. The making and wearing of cheongsam embody a kind of worship of natural beauty, but the pursuit of faithfully restoring the inherent tenderness of oriental women. Oriental women shoulder-cut, thin waist, narrow buttocks, small and round chest, gentle and elegant temperament, cheongsam will be the charm of oriental women to outline the perfect and amorous. Western exposure as sexy, and the East, especially in China, is specious, if there is no hazy sexy for the best. Soft lines, close to the package can always lead to unlimited reverie, on both sides of the slit, the hidden legs will be the ultimate interpretation of this hazy sexy. Cheongsam always knows Chinese women best, and only Chinese women can reveal the most beautiful side and the mellowest connotation of the cheongsam, except for the reasons for the different physical structure of Chinese and Western women. More deeply, there is the elegant and long charm of Chinese women engraved in the bone.

\section{B. Beauty of Cheongsam}

1) Implicit beauty: Because the cheongsam is closely sewn and close, it is inevitable that we will have restrictions on people's movement. Therefore, when we wear the cheongsam, we will consciously restrain our own behavior, and the extent of our activities will be reduced and we will even walk. The posture of sitting unconsciously revealed a trace of virtuous and noble taste. Cheongsam embodies the "elegance" and "softness" in traditional aesthetics. Demure and elegant is the traditional aesthetic standard of China, which is different from the "exposure" in the West, and the beauty in the "envelop" in the classical Chinese aesthetics. At the same time, through tight design, outline the beauty of the female curve, elegant and unpublicized collar, placket, sleeve, slit and other details of the embellishment of a beautiful and not evil, gentle, implicit beauty. This kind of beauty is different from the startling at the beginning. It needs to be carefully tasted and chewed, such as the tea fragrance, which is an aftertaste in "Fig. 6".

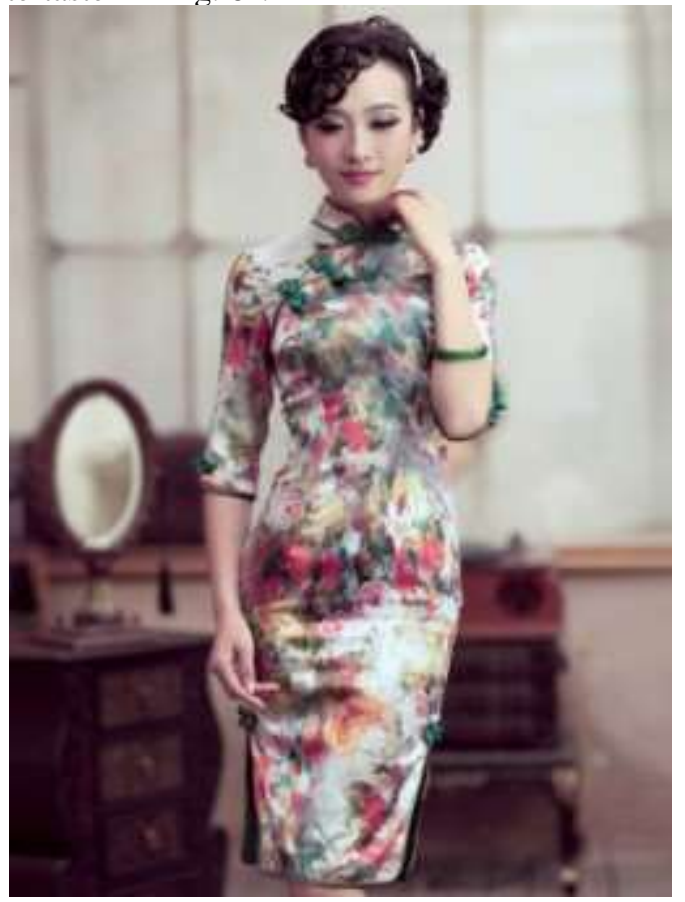

Fig. 6. The implicit beauty of Cheongsam.

2) The beauty of smart: On the beautiful cheongsam, we seem to see the smooth melody, the soft poetic sentiment and the painting style. The structure, shape and flowing lines of the dress are the rhyme of the cheongsam. In the traditional Chinese dress, the design and tailoring of the fitting body of the cheongsam is the most able to show the curves of the human body. The smooth, bright and unrestrained lines fully show the graceful curves of the shoulders, breasts, waists and buttocks of the oriental women. Put on a woman full of classical spiritual cheongsam, reverie, such as into the illusion, like the Jiangnan water country window overlooking the smart woman, eyes flow, bead swaying, amorous feelings infinite.

3) The beauty of neutralization: Confucianism has always occupied a dominant position in China, and the core of Confucianism is nothing more than "the middle way", which is the core of Chinese traditional aesthetics. Harmony requires moderation and coexistence, plump, not sudden, not predatory. Smart and introverted, noble and sexy, elegant and fashionable, these contradictory contradictions coexist harmoniously in cheongsam. The charm of cheongsam originates from the collision and coexistence of these contradictory elements-from the "neutralization" culture of China. Fit plane cut, smooth lines, aptamer's profile, collar, skirt, sleeve, slit and other details, after hundreds of years of development, these elements eventually precipitated, become the most classical and stable elements in cheongsam. Although these elements are not unique to cheongsam, they 
are only harmoniously combined as parts of cheongsam in "Fig. 7".

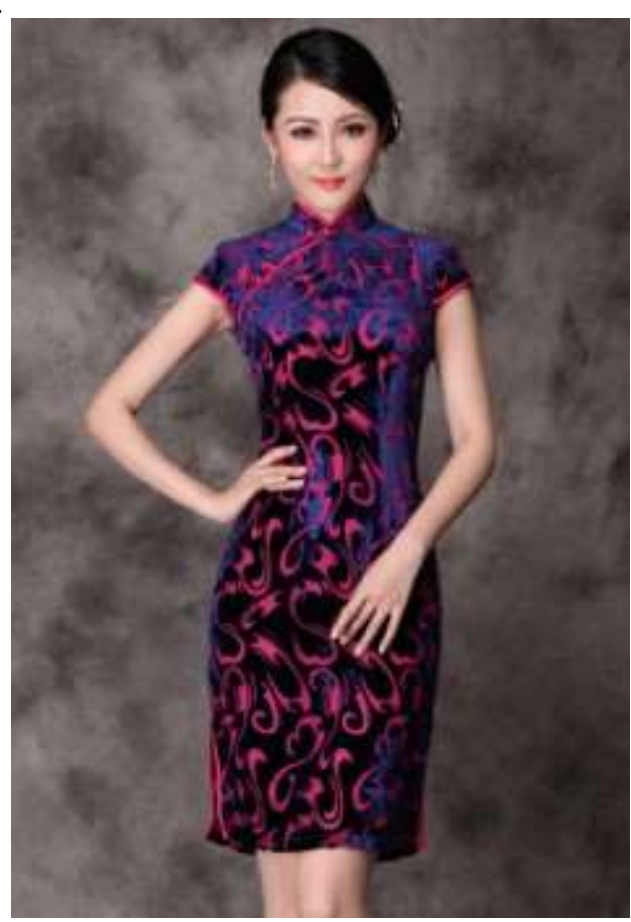

Fig. 7. The beauty of neutralization of cheongsam.

\section{ChInA's CHEONGSAM IN THE PROCESS OF IMPROVEMENT}

Needless to say, although cheongsam has many praiseworthy advantages, it also has some limitations. For example, because of the tight cut, the cheongsam has greatly restricted people's activities. Although it is not harmful to sitting up and walking, it is very inappropriate for people to reach out for a large amount of their hands and bend over to work. They are facing the new women, which is limited in popularity and practicability. In addition, the wearing of cheongsam requires a higher proportion of women's bodies, not to mention Western women with larger skeletons, and Chinese women who do not have a perfect figure, making it a shelved platform, a prohibitive piece of fine art. Therefore, in order to further promote the art and the culture of cheongsam, it is necessary to improve the design and technology of cheongsam from the perspective of the aesthetic characteristics, practicability and applicability of the times. This requires that China's cheongsam should proceed from the actual situation. Learn from Western dress culture, and fashion organic combination. Only rooted in the creation of national brand, with the modern design concept of tradition and fashion perfect fusion, in order to make the traditional Chinese dresscheongsam fresh, stand the test of time in all kinds of clothing trends in an invincible position.

\section{CONCLUSION}

After years of scouring and polishing, the cheongsam, became the eternal " fashion " capable of withstanding the test of time, a cultural symbol of a great nation, and made the oriental beauty of Chinese women to the extreme . However, while fully understanding the characteristics of cheongsam, excavating the beauty of the east and affirming the cultural value and aesthetic value of cheongsam, we should also realize the limitations of cheongsam. Only by combining the current popular culture and social reality, seeking the way to change the cheongsam, and making the cheongsam perfect day by day in the continuous improvement, can we continuously consolidate the position of the cheongsam in the international cultural and artistic palace Let China's traditional national dress bloom everlasting brilliance.

\section{REFERENCES}

[1] Zhang Junna; Zhang Huaxia. On the Aesthetic thinking of cheongsam under the influence of Modern Chinese Culture [J]. Tianjin Textile Technology .2016 (04) 张君娜;章华霞.论旗袍在中国现代文化影响下 的美学思考 [J].天津纺织科技.2016(04)

[2] Yan Qing. Cheongsam-opens the classical beauty of early summer [J]. Adolescent Health. 2018 (09) 艳青.旗袍——开启初夏古典之美[J].青 春期健康.2018(09)

[3] Zhang Min. On the analysis and development of custom brand of modern cheongsam [J]. Cultural Journal. 2017 (12) 张民. 论现代旗袍定 制品牌的分析与发展 [J].文化学刊.2017(12)

[4] Mao Huiwei. Brilliant hand achievement flag precious art treasure-on the beauty of cheongsam craft $[\mathrm{J}]$. Journal of Zhejiang Textile and clothing Vocational and Technical College .2018 (01) 茅惠伟.妙手成 就旗珍艺宝一一论旗袍工艺之美[J].浙江纺织服装职业技术学院学 报.2018(01)

[5] Xie Jundi. An Analysis of the Popularization method of innovative cheongsam in Modern Society [J]. Art Technology. 2016 (11) 谢俊迪. 浅析创新旗袍在现代社会中的推广方法[J].艺术科技.2016(11)

[6] Chen Dongsheng, Wei Xiaojuan, Zhou Liyan. The change of cheongsam and its oriental aesthetic features. Journal of Ningbi Vocational and Technical College of Garment [J] .4th issue, 2004 陈东 生、尉晓娟、周丽艳.旗袍的变革及其所体现的东方美学特征. 宁彼 服装职业技术学院学报 $[\mathrm{J}] .2004$ 年第 4 期

[7] Liu Yuhong, Yao Haiyan. On the Chinese culture embodied in cheongsam. Packaging [J] .2002 No. 2: 刘育红、姚海燕. 论旗袍中体 现出来的中国文化底蒀.包装工程 $[\mathrm{J}] .2002$ 年第 2 期:

[8] Zheng Miaoyang. Discussion on the characteristics and structure of cheongsam. Journal of Zhejiang Institute of Engineering [J] .3rd issue, 2001 郑苗种.旗袍的特性与结构探讨. 浙江工程学院学报 [ J ] .2001 年第 3 期

[9] Guo Fei. Looking at the trend of Chinese traditional dress culture from the change of cheongsam. Journal of Beijing Union University [J]. No. 4,2001 郭 斐.从旗袍的变革看中国传统服饰文化的走向. 北京联合大 学学报 $[\mathrm{J}] .2001$ 年第 4 期 